\title{
Health Protection Net
}

\author{
MiCHAEL SHARPE
}

$\mathrm{T}$ HE HEALTH PROTECTION BRANCH (HPB), HEALTH CANADA. is establishing a new electronic bulletin board system (BBS), Health Protection Net, as a single point for our partners to access a variety of branch information electronically. This information is currently supplied by four separate bulletin board systems throughout the branch from Food, Drugs, Environmental Health and the Laboratory Centre for Disease Control (LCDC) Directorates, with Field Operations having input into each system. Each directorate will continue to maintain its information on the new system.

As this article goes to press the new system is being configured and tested. Each directorate will commence promoting this new service to its clients in February 1994. The four existing BBSs will run in parallel for a short time until each directorate deems their BBs can be closed and transfer of data to the new one is complete.

Using information technology is key for the HPB to increase effectiveness and efficiency of service. By establishing Health Protection Net, the branch aims to communicate with, to disseminate information to and to receive information from our partners in Canada and internationally in a cost-effective manner. Health Protection Net will also assist in the interaction, coordination and flexibility of HPB programs and services and their delivery and will enhance communication and information sharing among HPB's partners.

Connection to Health Protection Net can be via a number of computer communication methods, such as direct dial modem, Datapac NUI and, most significantly, Internet. This will open access to the Canadian and international academic health researchers, health industry/manufacturers and the Canadian health care communities. Health Protection Net electronic mail is integrated with HPB and Internet electronic mail, allowing HPB staff to receive automatic notification of mail and attachments sent from the BBS and from the Internet. Databases and text information maintained by

Correspondence and reprints: Michael Sharpe, Senior Program Officer, Bureau of External Cooperation, Level AB, HPB Building, Ottawa, Ontario K1A OL2. Telephone (613) 954-3196. Fax (613) 954-5414, Internet msharpe@hpb.hwc.ca each directorate can be viewed, searched and saved to a client's own personal computer. Some databases and text information are value added cost recovery applications and will be accessible on a subscription basis.

Electronic conferences, on a variety of health related subjects, can be used for problem solving, newsletters, health alerts/bulletins, and health hazard outbreak investigation and control. File transfer can be used for many applications such as case, diagnostic and problem reporting. Access through Health Protection Net to international BBSs - such as the us Food and Drug Administration BBS, wHO NET Europe, the us Centers for Disease Control and Prevention, and others - are being arranged as they become available.

Health Protection Net is a valuable coordinating mechanism for each discipline and national project in the health field. No single national network exists through which health professionals can work together electronically (other than by telephone and fax). Some Canadian associations have set up or are establishing or contemplating their own electronic BBs. When they do so, it is hoped that links over the Internet can be built between the information network of HPB and each health association's network. In this way Canada will develop a single comprehensive health net running over CANARIE, the Canadian Network for the Advancement of Research, Industry and Education, Canada's electronic superhighway that is under development in partnership with the business, research and government communities. Health Protection Net is being regarded by Communications Canada/Industry Canada as the foundation for developing the health component to CANARIE, Health Net.

The importance of sharing information through a common network was reinforced recently at the LCDC sponsored workshop of the Expert Working Group on Emerging Infectious Disease Issues held at Mont Tremblant, Quebec. The common network was listed as the most crucial, overall recommendation that would enable public health professionals to carry on successfully the new collaborative and consultative approaches needed for the surveillance and control of emerging pathogens. Access to the latest infectious disease re- 
ports, to colleagues at Health Canada, and to each other is an important mechanism that health professionals require to keep pace with the changes and incidents of infectious diseases as they appear.

It was agreed that networking is needed not only between disciplines and across Canada, but so too is access to international information; cooperation was also deemed essential in the network's capabilities. Emergent and resurgent infectious diseases were affirmed by the working group to be a global issue, and Canada must be tied into the electronic network of international health information to better plan and prepare for potential outbreaks that could arrive from elsewhere in the world or originate here, spread and be carried elsewhere. The Tremblant workshop began the development of the Canadian portion of global surveillance of emergent and resurgent infectious diseases.
The Health Protection Net BBS is a tool for greater collaboration and consultation by all health professionals to develop more effective and efficient surveillance and control mechanisms of infectious diseases.

HPB's first partner in the BBS is the Medical Research Council, who will also provide access to a variety of information. Other groups within Health Canada are also interested in providing their information. LCDC and the other HPB directorates will be distributing information kits to their clients in April 1994. These kits will contain greater detail on Health Protection Net and will explain how computers connect to it and how to register online. This BBS is designed for our partners. HPB will need ongoing feedback to tell us what is useful and what is unclear about the system. This will enable the BBS to change and grow to best suit user needs. 


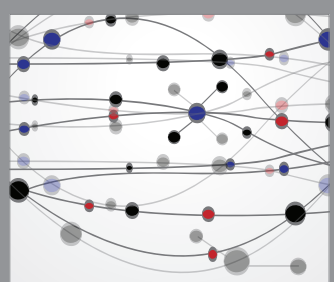

The Scientific World Journal
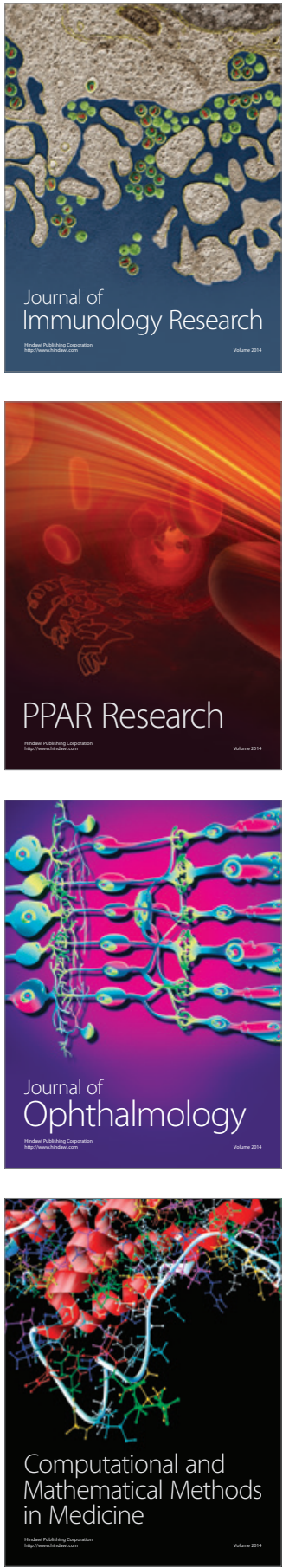

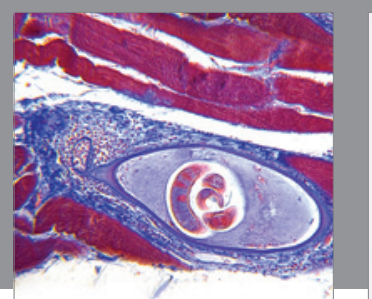

Gastroenterology Research and Practice

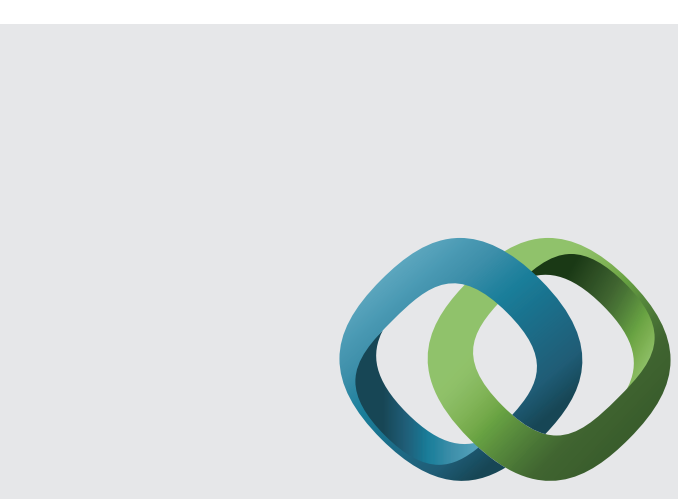

\section{Hindawi}

Submit your manuscripts at

http://www.hindawi.com
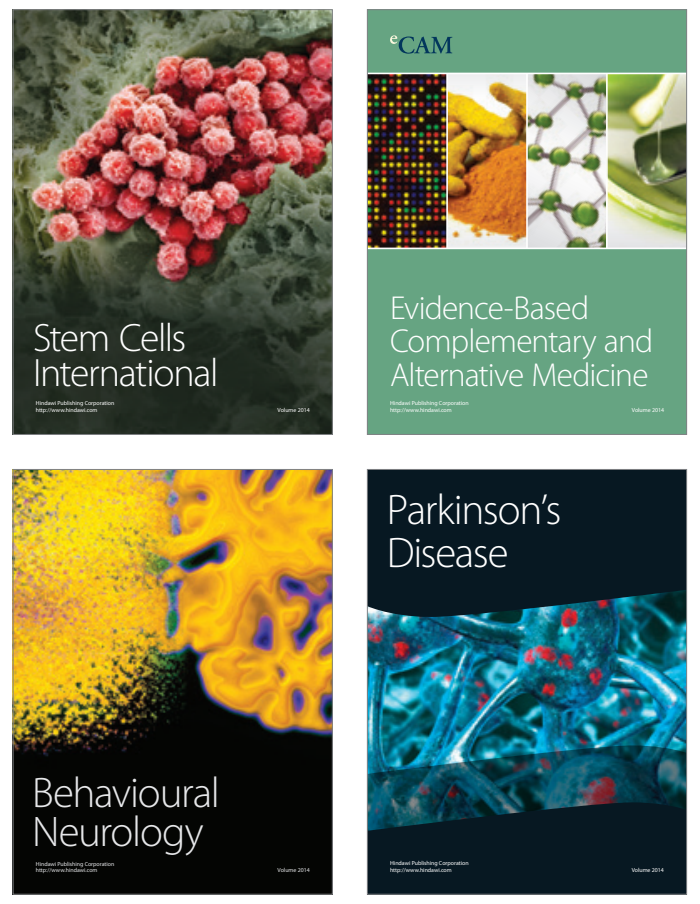
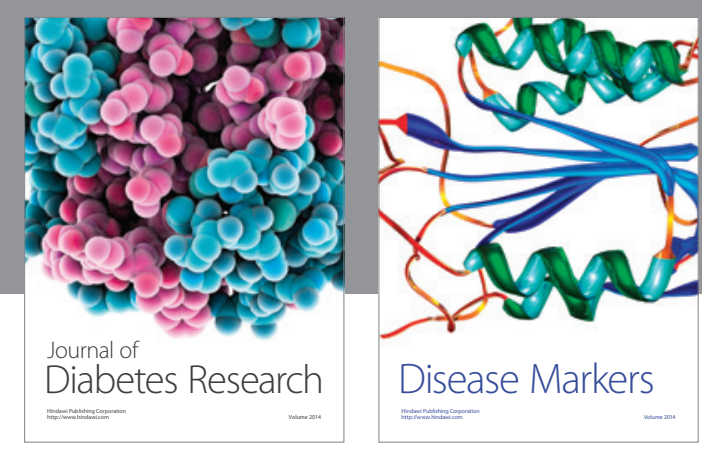

Disease Markers
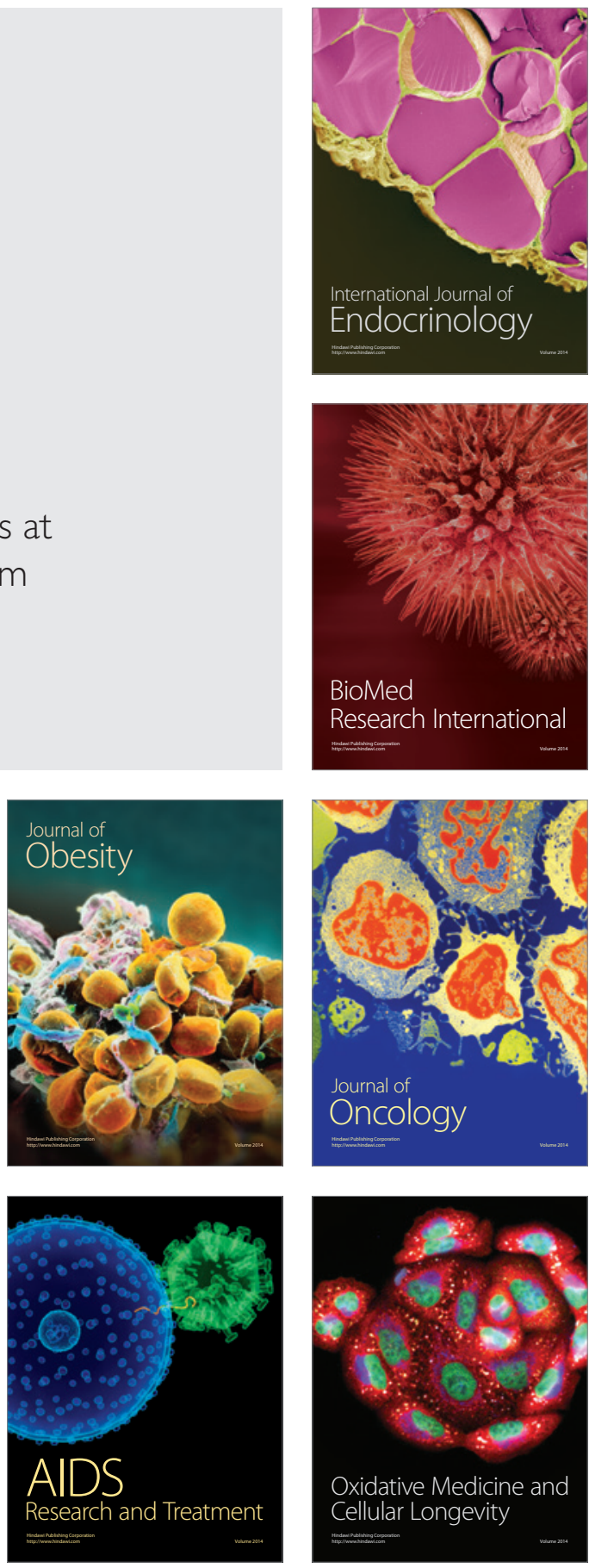